\title{
Excessive secretion of antidiuretic hormone in infections with respiratory syncytial virus
}

\author{
Department of \\ Paediatrics, \\ Sophia Children's \\ Hospital, \\ Erasmus University, \\ Gordelweg 160, \\ 3038 GE Rotterdam, \\ The Netherlands \\ Henriëtte A van \\ Steensel-Moll \\ Herman J Neijens \\ Division of Paediatric \\ Intensive Care, \\ Sophia Children's \\ Hospital, \\ Rotterdam \\ Jan A Hazelzet \\ Edwin van der Voort \\ Municipal Hospital \\ Bergwegziekenhuis, \\ Endocrinologic \\ Laboratory, \\ Rotterdam \\ Wil H L Hackeng \\ Correspondence to: \\ Dr van Steensel-Moll. \\ Accepted 17 May 1990
}

Henriëtte A van Steensel-Moll, Jan A Hazelzet, Edwin van der Voort, Herman J Neijens, Wil H L Hackeng

\begin{abstract}
The association between infections with respiratory syncytial virus and plasma concentrations of antidiuretic hormone was assessed in $\mathbf{4 8}$ patients who had been admitted to hospital. The mean (SEM) concentration of antidiuretic hormone was significantly raised in patients with bronchiolitis (9.3 (1.4) ng/1) compared with nonpulmonary respiratory syncytial virus infections that cause apnoea or upper respiratory tract symptoms $(6.1(1.7) \mathrm{ng} / \mathrm{l})$. The highest concentrations of antidiuretic hormone were seen in patients receiving mechanical ventilation (18.0 $(6 \cdot 7) \mathrm{ng} / \mathrm{l})$. There were no differences in mean serum sodium concentrations among the subgroups. Hypertranslucency on chest radiograph or an arterial carbon dioxide tension above $\mathbf{6 . 6 7}$ kPa were associated with a significantly higher concentration of antidiuretic hormone. Increased or normal maintenance fluid intake in children with pulmonary respiratory syncytial virus infections may cause the same symptoms of fluid overload as the syndrome of inappropriate secretion of antidiuretic hormone. Patients with pulmonary respiratory syncytial virus infection, hypertranslucency in chest radiograph, hypercapnia, or mechanical ventilation are at risk for raised concentrations of antidiuretic hormone.

Restricted fluid intake and careful monitoring of fluid balance and plasma electrolyte concentrations are therefore necessary in these patients.
\end{abstract}

Decreased renal water excretion is a feature of various pulmonary disorders including viral and bacterial pneumonia, pneumothorax, atelectasis, and acute asthmatic attacks. ${ }^{1-6}$ Some studies have also reported increased concentrations of antidiuretic hormone. ${ }^{3-5} 7$ Many infants admitted to hospital with respiratory syncytial virus bronchiolitis will receive intravenous fluids because of feeding difficulties as a result of dyspnoea. In cases of inappropriate secretion of antidiuretic hormone, fluid overload may lead to accumulation of fluid in the lungs, which will further increase respiratory insufficiency in respiratory syncytial virus bronchiolitis. ${ }^{89}$

The aim of this study was to relate the severity of respiratory syncytial virus infections to plasma concentrations of antidiuretic hormone to find out which patients are at risk of inappropriate secretion of antidiuretic hormone.

\section{Patients and methods}

The Sophia Children's Hospital is a tertiary referral centre, and therefore a high percentage of high risk infants and ventilated patients are included in this study. ${ }^{6}{ }^{10}$ Forty eight patients with respiratory syncytial virus infections who were admitted to hospital because of apnoea, dyspnoea, or feeding difficulties were included in this prospective study (15 October 1987 to 1 April 1988). Respiratory syncytial virus was diagnosed by the direct immunofluorescence test of nasopharyngeal secretion (Boots Cell Tech) and culture of the virus.

Age, sex, and medical history were recorded on admission. The diagnosis of bronchiolitis was based on clinical features (tachypnoea, recession, wheezing, and diffuse fine rales). Apnoea was defined as cessation of respiration for longer than 15 seconds, or a history of cessation of breathing associated with cyanosis.

No treatment known to interfere with secretion of antidiuretic hormone was given. All patients received a fluid intake that was two thirds of the normal maintenance amount.

On admission arterial carbon dioxide tension $\left(\mathrm{PaCO}_{2}\right)$ was measured in capillary arterial blood and antidiuretic hormone and plasma sodium concentrations were measured in venous blood.

Samples for assay of antidiuretic hormone were collected by venepuncture and centrifuged immediately; EDTA was used as the anticoagulant. The plasma was stored at $-70^{\circ} \mathrm{C}$ until assay. Antidiuretic hormone was measured with the INCSTAR radioimmunoassay system (Stillwater, Minnesota); it was extracted from acidified EDTA plasma with OSD silica (Waters Associates) and eluted with methanol. The effluent was blow dried at $37^{\circ} \mathrm{C}$ with nitrogen. Extraction recovery was about $91 \%$, and the antidiuretic hormone concentrations were not corrected for extraction loss. At concentrations of 1.2 and $10 \mathrm{ng} / 1$ the intra-assay and interassay coefficients of variation were $11 \%$ and $5 \%$, and $3 \%$ and $4 \%$, respectively. The mean normal adult value is $1.4 \mathrm{ng} / 1$ (reference range $0 \cdot 5-4 \cdot 7$ ng/l).

A chest radiograph was done on admission, which was reviewed by a paediatric radiologist who had no knowledge of the diagnosis or complications.

\section{EVALUATION OF DATA}

Patients were divided into subgroups depending on the clinical diagnosis (pulmonary respiratory syncytial virus infection - that is, bronchiolitis or pneumonia, or both-and non-pulmonary respiratory syncytial virus infection-that is, apnoea or upper respiratory tract infections). Patients with neither clinical nor radiological signs of pulmonary disease were classified as non-pulmonary respiratory syncytial virus. A further subdivision based on the findings on chest radiography (normal, atelectasis or infiltrate(s), or both, or hypertranslucency) was made. Patients receiving mechanical ventilation were considered as a separate subgroup.

The Mann-Whitney U test was used to assess differences between concentrations of antidiuretic 
Table 1 Plasma antidiuretic hormone and serum sodium concentrations in 48 patients

\begin{tabular}{llll}
\hline & $\begin{array}{l}\text { Patients with } \\
\text { non-pulmonary } \\
\text { infections } \\
(n=11)\end{array}$ & $\begin{array}{l}\text { Patients with } \\
\text { bronchiolitis } \\
\text { and/or pneumonia } \\
(n=28)\end{array}$ & $\begin{array}{l}\text { Patients receiving } \\
\text { mechanical } \\
\text { ventilation } \\
(n=9)\end{array}$ \\
\hline $\begin{array}{l}\text { Plasma antidiuretic hormone (ng/): } \\
\begin{array}{l}\text { Mean (SEM) } \\
\text { Range }\end{array}\end{array}$ & $\begin{array}{l}6 \cdot 1(1 \cdot 7) \dagger \\
1 \cdot 2-21\end{array}$ & $\begin{array}{l}9 \cdot 3(1 \cdot 4) \\
1 \cdot 0-26\end{array}$ & $\begin{array}{c}18 \cdot 0(6 \cdot 7) \\
2 \cdot 1-69\end{array}$ \\
$\begin{array}{l}\text { Serum sodium (mmol/): } \\
\quad \text { Mean (SEM) } \\
\text { Range }\end{array}$ & $138(0 \cdot 8)$ & $138(0.5)$ & $136(2 \cdot 0)$ \\
\hline
\end{tabular}

${ }^{*} p<0.01$ compared with patients receiving mechanical ventilation.

tp $<0.05$ compared with patients receiving mechnical ventilation.

hormone or between plasma sodium concentrations in the different subgroups. Patients receiving mechanical ventilation were excluded from the analysis of $\mathrm{PaCO}_{2}$ and chest radiographs. Approval was obtained from the institutional review board for the study. Informed consent after full information had been given was received for all patients.

\section{Results}

The median age of the patients was 104 days, and $38(79 \%)$ were less than 1 year old on admission. The boy:girl ratio was $1 \cdot 3$, and a quarter were born prematurely; none had bronchopulmonary dysplasia. None of the children was clinically dehydrated on admission (loss of weight, oedema, or dry mucous membranes).

Increased plasma concentrations of antidiuretic hormone $(>4.7 \mathrm{ng} / \mathrm{l})$ were found in 27 patients

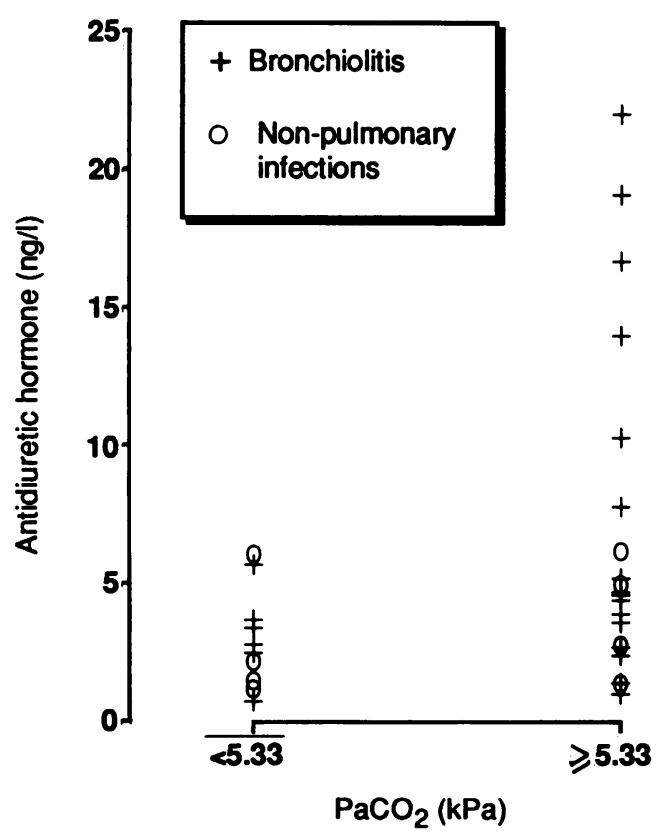

Association between plasma antidiuretic hormone concentrations and $\mathrm{PaCO}_{2}$.
$(56 \%)$. In 10 patients $(21 \%)$ the plasma sodium concentrations were less than $135 \mathrm{mmol} / \mathrm{l}$ on admission (reference range $135-145 \mathrm{mmol} / \mathrm{l}$ ).

The concentrations of antidiuretic hormone were significantly raised in patients with bronchiolitis compared with patients with non-pulmonary respiratory syncytial virus infection resulting in apnoea or upper respiratory tract symptoms alone. The concentrations of antidiuretic hormone were highest in the patients receiving mechanical ventilation; the difference was significant (table 1).

The plasma sodium concentrations in patients with bronchiolitis, patients with non-pulmonary respiratory syncytial virus infection, and patients receiving mechanical ventilation were not significantly different (table 1).

The figure shows the association between $\mathrm{PaCO}_{2}$ and antidiuretic hormone concentration. The number of patients with concentrations of antidiuretic hormone above $4 \cdot 7 \mathrm{ng} / 1$ increased as the $\mathrm{PaCO}_{2}$ increased. The concentration of antidiuretic hormone was increased in five of 14 patients $(36 \%)$ when the $\mathrm{PaCO}_{2}<5.33 \mathrm{kPa}$, in 11 out of $21(52 \%)$ with a $\mathrm{PaCO}_{2}$ between 5.33 and $6.53 \mathrm{kPa}$, and in all patients with a $\mathrm{PaCO}_{2} \geqslant 6.67$ $\mathrm{kPa}$. Significantly higher concentrations of antidiuretic hormone were found in patients with a $\mathrm{PaCO}_{2}>6.67 \mathrm{kPa}$ compared with patients in whom they were $<5.33 \mathrm{kPa}(\mathrm{p}<0.05)$.

The mean plasma concentrations of antidiuretic hormone and the findings on chest radiography are shown in table 2. Hypertranslucency on the chest radiograph was associated with considerably increased concentrations of antidiuretic hormone compared with the concentrations when the radiograph was normal or showed infiltrate(s) or atelectasis, or both. There were no significant differences in plasma sodium concentrations among the subgroups, nor was any association found between findings on chest radiography and $\mathrm{PaCO}_{2}$.

\section{Discussion}

The results of this study showed that patients with respiratory syncytial virus infections resulting in bronchiolitis, hypertranslucency on the chest radiograph, hypercapnia, or requiring mechanical

Table 2 Plasma antidiuretic hormone concentrations and results of chest radiography in 37 patients

\begin{tabular}{|c|c|c|c|}
\hline & \multicolumn{3}{|c|}{ Chest radiograph } \\
\hline & $\begin{array}{l}\text { Normal } \\
(n=14)\end{array}$ & $\begin{array}{l}\text { Showing atelectasis/ } \\
\text { infiltrate(s) } \\
(n=7)\end{array}$ & $\begin{array}{l}\text { Showing } \\
\text { hyperinflation } \\
(n=16)\end{array}$ \\
\hline $\begin{array}{l}\text { Plasma antidiuretic hormone (ng/l): } \\
\text { Mean (SEM) } \\
\text { Range }\end{array}$ & $\begin{array}{l}7.0(1.5) \\
2 \cdot 3-24\end{array}$ & $\begin{array}{l}5 \cdot 5(2 \cdot 1) \\
1 \cdot 0-17\end{array}$ & ${ }_{1-26}^{11 \cdot 3}(2 \cdot 0)^{*}$ \\
\hline
\end{tabular}

"p<0.05 compared with each of the other groups. 
ventilation are at risk for increased concentrations of antidiuretic hormone. There were no significant differences in plasma sodium concentrations among the subgroups. The association between certain pulmonary processes and hyponatraemia has been known for nearly 50 years. In the 1950s the pathophysiology of hyponatraemia in pulmonary disorders was linked to inappropriate secretion of antidiuretic hormone. Since then several authors have reported hyponatraemia in association with pulmonary disorders in childhood. ${ }^{1-3} 5$ 11-13 In a few studies in children antidiuretic hormone concentrations were measured. One study reported a pronounced increase in concentrations of antidiuretic hormone during a severe asthmatic episode. No appreciable differences were found in plasma sodium concentration, plasma osmolality or urine osmolality between the asthmatic and control groups. ${ }^{3}$ Two cases in which raised antidiuretic hormone concentrations were associated with respiratory syncytial virus bronchiolitis were reported; raised concentrations of antidiuretic hormone were also found in infants with bronchopulmonary dysplasia during periods of acute respiratory distress-all these infants suffered from hypoxaemia with air trapping. Gozal $e t$ al have recently reported raised concentrations of antidiuretic hormone in infants with bronchiolitis of various aetiologies. ${ }^{7}$

Several pathophysiological mechanisms might explain our findings. The secretion of antidiuretic hormone is a homoeostatic process guided by alterations in the volume of intravascular fluid and by the osmolality of the extracellular fluid. Volume receptors are located in the left atrium, baroreceptors in the carotid arteries and the aortic arch, and osmoreceptors in the supraoptic and paraventricular nuclei of the hypothalamus. Hyperinflation of the lungs causes pulmonary hypovolaemia and decreases left atrial filling or transmural pressure of the left atrium, or both, and subsequently increases production of antidiuretic hormone. 3511 It has been suggested recently that pneumonia may increase antidiuretic hormone concentrations by altering the osmoregulation of central antidiuretic hormone release so that a lower plasma osmolality is required to suppress antidiuretic hormone release fully. ${ }^{4}$ This hypothesis explains why plasma sodium concentrations remain within the reference range in patients with raised concentrations of antidiuretic hormone.

Patients receiving mechanical ventilation have the highest plasma antidiuretic hormone concentrations; this can be explained by the severity of the pulmonary disease itself and by ventilation with positive end expiratory pressure (PEEP), which is known to increase antidiuretic hormone secretion. ${ }^{12-14}$

Experimental and clinical observations have suggested that hypoxaemia and hypercapnia stimulate release of antidiuretic hormone. ${ }^{15}$ In this study a large number of patients with a $\mathrm{PaCO}_{2}$ above $5.33 \mathrm{kPa}$, which can be considered as pathologically increased if tachypnoea is present, had raised antidiuretic hormone concentrations.

The increased antidiuretic hormone concentrations in pulmonary respiratory syncytial virus infections might be attributed to an interaction between osmotic control of antidiuretic hormone and a false haemodynamic signal of volume depletion. Three conditions might lead to aggravation of respiratory insufficiency in patients with respiratory syncytial virus bronchiolitis: firstly, increased negative pleural pressure in bronchiolitis might cause pulmonary fluid accumulation ${ }^{16}$; secondly, increased concentrations of leucotrienes were found in the nasal fluid of children with bronchiolitis, ${ }^{17}$ and if these are also present in pulmonary tissue vascular permeability may be enhanced resulting in pulmonary fluid accumulation; and thirdly, increased or normal maintenance fluid intake in children with pulmonary respiratory syncytial virus infections will cause the clinical symptoms of fluid overload resulting from inapproriate secretion of antidiuretic hormone.

In conclusion, patients with severe pulmonary respiratory syncytial virus infections are at the risk of hyponatraemia if excessive amounts of hypotonic fluids are given. Restriction of fluid intake seems to be necessary, especially in children with severe bronchiolitis. None of the patients in this study developed inappropriate secretion of antidiuretic hormone while they were in hospital. Careful monitoring of fluid balance and plasma electrolyte concentrations is necessary to avoid a potentially harmful iatrogenic disorder.

We thank $M$ Meradji MD, $\mathrm{PhD}$, for reviewing the chest radiographs and $\mathrm{PhH}$ Rothbarth $\mathrm{MD}, \mathrm{PhD}$, for undertaking the virological studies.

I Rivers RPA, Forsling ML, Olver RP. Inappropriate secretion of antidiuretic hormone in infants with respiratory infections. Arch Dis Child 1981;56:358-63.

2 Shann F, Germer S. Hyponatraemia associated with pneumonia or bacterial meningitis. Arch Dis Child 1985;60:963-6.

3 Dawson KP, Fergusson DM, West J, et al. Acute asthma and antidiuretic hormone secretion. Thorax 1983;38:389-94.

4 Dreyfuss D, Leviel F, Paillard M. Acute infectious pneumonia is accompanied by a latent vasopressin-dependent impairment of renal water excretion. Am Rev Respir Dis 1988;138:583-9.

5 Rao M, Eid N, Henod L, Parekh A, Steiner P. Antidiuretic hormone response in children with bronchopulmonary dysplasia during episodes of acute respiratory distress. $A m$ f Dis Child 1986;140:825-8.

6 Van Steensel HA, van der Voort E, Bos AP, et al. Respiratory syncytial virus infections in children admitted to the intensive care unit. Pediatrie 1989;44:583-8.

7 Gozal D, Dolin AA, Jaffe M, Hochberg Z. Water, electrolyte and endocrine homeostasis in infants with bronchiolitis. Pediatr Res 1990;27:204-9.

8 Segar WE, Friedman AL. Primary disturbances of water homeostasis. In: Rudoph AM, Hoffmann JIE, eds.

Pediatrics. Connecticut: Prentice Hall, 1987:1469-70. Forfar JO, Arneill GC, eds. Respiratory disorders. Textbook of pediatrics. Edinburgh: Churchill Livingstone, 1984:548.

10 Van Steensel-Moll HA, Tissing WJE, Offringa M, Hazelze JA. Mechanical ventilation and respiratory syncytial virus
infection. Arch Dis Child 1990;65:332. infection. Arch Dis Child 1990;65:332.

11 Friedman AL, Segar WE. Antidiuretic hormone excess. f Pediatr 1979;94:521-6.

12 Pomarede A, Moriette G, Czernichow P, et al. Etude de la vasopressine plasmatique chez les enfants prématures soumis à la ventilation artificielle. Arch Fr Pediatr 1978;35: $75-83$.

13 Matherne P, Matson J, Marks MI. Pertussis complicated by the syndrome of inappropriate antidiuretic hormone secretion. Clin Pediatr 1986;25:46-8.

14 Dixon BS, Anderson RJ. Pneumonia and the syndrome of inappropriate antidiuretic hormone secretion: don't pour water on the fire. Am Rev Respir Dis 1988;138:512-3.

15 Rose EC, Dixon BS, Anderson RJ. Water metabolism in respiratory disorders. Semin Nephrol 1984;4:295-302.

16 Stalcup SA, Mellins RB. Mechanical forces producing pulmonary.

17 Volovitz B, Welliver RC, de Castro G, et al. The release of leukotrienes in the respiratory tract during infection with respiratory syncytial virus: role in obstructive airway disrespiratory syncytial virus: role in
ease. Pediatr Res 1988;24:504-7. 